\title{
HCV co-infection and markers of liver injury and fibrosis among HIV-positive childbearing women in Ukraine: results from a cohort study
}

Heather Bailey ${ }^{1 *}$, Nataliya Nizova ${ }^{2}$, Violeta Martsynovska ${ }^{2,3}$, Alla Volokha $^{4}$, Ruslan Malyuta ${ }^{5}$, Mario Cortina-Borja ${ }^{1}$, Claire Thorne ${ }^{1}$ and the Ukraine European Collaborative Study in EuroCoord

\begin{abstract}
Background: Ukraine's injecting drug use-driven HIV epidemic is among the most severe in Europe with high burden of HCV co-infection. HIV/HCV co-infected individuals are at elevated risk of HCV-related morbidity, but little is known about burden of liver disease and associated factors in the HIV-positive population in Ukraine, particularly among women.
\end{abstract}

Methods: Characteristics of 2050 HIV-positive women enrolled into the Ukrainian Study of HIV-infected Childbearing Women were described by HCV serostatus. Aspartate transaminase (AST) to platelet ratio (APRI) and FIB-4 scores were calculated and exact logistic regression models fitted to investigate factors associated with significant fibrosis (APRI >1.5) among 762 women with an APRI score available.

Results: Of 2050 HIV-positive women (median age 27.7 years, IQR 24.6-31.3), 33\% were HCV co-infected (79\% of those with a history of injecting drug use vs $23 \%$ without) and $17 \% \mathrm{HBsAg}$ positive. A quarter were on antiretroviral therapy at postnatal cohort enrolment. $1 \%$ of the HIV/HCV co-infected group had ever received treatment for HCV. Overall, 24\% had an alanine aminotransferase level $>41 \mathrm{U} / \mathrm{L}$ and 34\% an elevated AST (53\% and 61\% among HIV/ HCV co-infected). Prevalence of significant fibrosis was 4.5\%; 2.5\% among 445 HIV mono-infected and $12.3 \%$ among 171 HIV/HCV co-infected women. 1.2\% had a FIB-4 score $>3.25$ indicating advanced fibrosis. HCV RNA testing in a sub-group of $56 \mathrm{HIV} / \mathrm{HCV}$ co-infected women indicated a likely spontaneous clearance rate of $18 \%$ and predominance of HCV genotype 1, with one-third having genotype 3 infection. Factors associated with significant fibrosis were HCV co-infection (AOR 2.53 95\%Cl 1.03-6.23), history of injecting drug use (AOR 3.51 95\%Cl 1.39-8.89), WHO stage 3-4 HIV disease (AOR 3.47 95\% CI 1.51-7.99 vs stage 1-2 HIV disease) and not being on combination antiretroviral therapy (AOR 3.08 95\%Cl 1.23-7.74), adjusted additionally for HBV co-infection, smoking and age.

Conclusions: Most HIV/HCV co-infected women had elevated liver enzymes and 12\% had significant fibrosis according to APRI. Risk factors for liver fibrosis in this young HIV-positive population include poorly controlled HIV and high burden of HCV. Results highlight the importance of addressing modifiable risk factors and rolling out HCV treatment to improve the health outcomes of this group.

Keywords: HIV, Hepatitis C, Women, Liver fibrosis, Ukraine, APRI, FIB-4, Combination antiretroviral therapy, Eastern Europe

\footnotetext{
* Correspondence: heather.bailey@ucl.ac.uk

${ }^{1}$ Population, Policy and Practice Programme, UCL Great Ormond Street Institute of Child Health, University College London, 30 Guilford Street, London WC1N 1EH, UK

Full list of author information is available at the end of the article
} International License (http://creativecommons.org/licenses/by/4.0/), which permits unrestricted use, distribution, and reproduction in any medium, provided you give appropriate credit to the original author(s) and the source, provide a link to the Creative Commons license, and indicate if changes were made. The Creative Commons Public Domain Dedication waiver (http://creativecommons.org/publicdomain/zero/1.0/) applies to the data made available in this article, unless otherwise stated. 


\section{Background}

An estimated 184 million people or $2.8 \%$ worldwide are seropositive for hepatitis $\mathrm{C}$ virus (HCV) [1] with infections in Europe concentrated within non-EU/ EFTA countries [2]. Prevalence of anti-HCV and hepatitis B surface antigen (HBsAg) are both substantially higher among people living with HIV but vary between populations, reflecting differing modes of HIV acquisition [3]. In Eastern Europe and Central Asia, where the HIV epidemic has historically been driven by injecting drug use (IDU), around $40 \%$ of people living with HIV are $\mathrm{HCV}$ co-infected, accounting for over a quarter of $\mathrm{HIV} / \mathrm{HCV}$ co-infections worldwide [3]. As in Western Europe, genotype (GT) 1 predominates [4].

Liver disease is a leading cause of death among HIVpositive populations, with severe immunosuppression associated with liver-related death independently of viral hepatitis co-infection [5]. HCV-related liver disease progression is accelerated in the presence of HIV coinfection [6] and the large reductions in mortality risk seen with combination antiretroviral therapy (cART) in HIV mono-infected individuals are not matched in HIV/ $\mathrm{HCV}$ co-infected patients [7]. Although studies of $\mathrm{HCV}$ mono-infection have indicated slower liver disease progression in pre-menopausal women than in men, due to oestrogen-mediated and other effects [8], whether this is true for women co-infected with HIV remains unclear [9]. Other factors associated with faster liver fibrosis progression in $\mathrm{HIV} / \mathrm{HCV}$ co-infection include older age at diagnosis, longer duration of infection, lower CD4 count and alcohol use [10]. HIV/HCV co-infected pregnant women have a vertical $\mathrm{HCV}$ transmission risk of around $10-11 \%$, almost twice that of HCV monoinfected women [11].

Despite historically worse outcomes with interferonbased $\mathrm{HCV}$ treatment, $\mathrm{HIV} / \mathrm{HCV}$ co-infected patients treated with directly acting antivirals (DAA) can now expect outcomes on a par with HCV mono-infected individuals [12-14]. However, the high cost of DAAs currently limits access, particularly in low and middle income countries [15].

Quantification of liver fibrosis and associated risk factors among people living with HIV is important in understanding potential future liver disease burden, to inform policies for minimising the impact of modifiable risk factors on disease progression and for identifying groups most urgently requiring $\mathrm{HCV}$ treatment. The FIB-4 index and the aspartate transaminase (AST) to platelet ratio (APRI) are algorithms allowing calculation of a score indicating likelihood of significant or advanced fibrosis from routinely available blood tests [16, 17]; these surrogate markers have been validated in HIV/ $\mathrm{HCV}$ co-infected adults and are particularly useful for assessing liver fibrosis in resource-constrained settings such as Ukraine, where other non-invasive measures such as hepatic transient elastography or direct serologic markers are unavailable.

The overall aim of this study was to investigate markers of liver injury (i.e. elevated transaminases) and fibrosis in postnatal women living with HIV with and without HCV-co-infection in Ukraine. Specific objectives were to assess the prevalence of and factors associated with significant liver fibrosis, as measured by surrogate biomarkers, and to describe $\mathrm{HCV}$ viral characteristics (GT and viral load) for a sub-set of $\mathrm{HIV} / \mathrm{HCV}$ coinfected women.

\section{Methods}

\section{Study population}

The Ukrainian Study of HIV-infected Childbearing Women, nested within the Ukraine European Collaborative Study (ECS), enrolled HIV-positive childbearing women with informed consent at five regional HIV/ AIDS centres in Ukraine between 2007 and 2012, around 3-6 months after delivery [18]. Clinical data reported by the clinician included HIV co-infections, liver function test (LFT) and haematological test results, HIV disease status and ART. Women self-reported sociodemographic characteristics and health behaviours (including drug use and smoking). Updated clinical data were collected at routine follow-up visits. Unique study numbers were used to match records from this postnatal cohort with those in the Ukraine ECS, to obtain data on antenatal ART use and timing of HIV diagnosis [19].

As HCV GT and HCV RNA tests are not part of routine clinical care in Ukraine, information on these factors were sought as part of a sub-study from March to July 2013 in $56 \mathrm{HIV}$-positive HCV-seropositive women who had never received $\mathrm{HCV}$ treatment and consented for these additional tests. The 56 women were recruited at one regional centre (in Kiev), and all HCV GT and RNA tests were conducted at the same lab using real time PCR amplificator Rotor-Gene ("Corbett Research", Australia) and AmpliSense HCV-genotype-FL test kits, Russia, sensitivity 5x1000 IU/ml (1.35x10000 copies/ml).

Analyses were conducted among the 2050 women enrolled in the postnatal cohort with HCV serostatus available, and the sample of 56 women with additional HCV test results. The presence of liver fibrosis was assessed based on APRI and FIB-4.

The ECS has ethics approval from the Great Ormond Street Hospital for Children NHS Trust/Institute of Child Health Research Ethics Committee (reference 96 EB02). Ethics approval for additional HCV RNA and GT testing conducted with consent as part of this study was obtained from the UCL Research Ethics Committee (3061/002) and from the Ethics Committee of the 
Shupyk National Medical Academy of Postgraduate Education in Kiev.

\section{Definitions}

APRI scores were calculated as (AST/upper limit of normal [ULN]) /platelet count $\mathrm{x} 100$, with values of $<0.5$ indicating the absence and values of $>1.5$ indicating the presence of significant liver fibrosis (equivalent to METAVIR $\geq$ F2) [16]. FIB-4 scores were calculated using age and AST, alanine aminotransferase (ALT) and platelet levels. FIB-4 scores of $<1.45$ indicate absence of fibrosis and those $>3.25$ indicate advanced fibrosis (METAVIR $\geq$ F3) [17]. Scores for each measure which fell between the two cut-offs were defined as indeterminate.

Hepatitis B co-infected women were defined as those positive for $\mathrm{HBsAg}$ and $\mathrm{HCV}$ co-infected women as those with HCV antibodies. The ULN was taken as 38 $\mathrm{U} / \mathrm{L}$ for AST and $41 \mathrm{U} / \mathrm{L}$ for ALT [20]; an ULN of 19 was also used to describe ALT measures, as this lower ULN may be more sensitive in identifying individuals with liver injury / hepatitis C viremia [21]. LFT elevations were categorised as mild, moderate or severe /potentially life threatening using the Division of AIDS (DAIDS) grading criteria [22]. IDU was defined by selfreport, clinical assessment or neonatal abstinence syndrome in the woman's infant (apparent in $60-80 \%$ of infants exposed to opiates in-utero [23]). Smoking status was determined at postnatal cohort enrolment.

\section{Selection of LFTs for analysis and calculation of APRI and FIB-4}

The first eligible liver function and platelet results reported after delivery were used to calculate one APRI and one FIB-4 score for each woman; eligible test results were based on $\geq 1$ blood samples taken within seven days. Results taken during pregnancy were excluded. Women with no LFTs reported up to their last date of follow-up or up to three years after delivery (whichever was earlier) were excluded, as were any women whose first results reported were during a subsequent pregnancy, due to the normal fluctuations in ALT, AST and platelet levels which occur during pregnancy [20] potentially affecting the validity of APRI and FIB-4. Women missing hepatitis B status $(n=95)$ were excluded from analyses of LFTs, APRI and FIB-4 scores.

\section{Statistical analysis}

Chi-squared or Fisher's exact tests were used for univariable comparisons of categorical variables and the Wilcoxon-Mann-Whitney rank sum test for comparing location in continuous variables. Exact logistic regression models were fitted to assess factors associated with significant fibrosis (i.e. APRI score >1.5), but not for advanced fibrosis (i.e. FIB- $4>3.25$ ), as the low prevalence of this more severe outcome precluded adjusted analyses. Variables associated with the outcome $(p<0.1)$ in univariable analyses were included in the multivariable model, in addition to hepatitis B co-infection status and postnatal ART use a priori. An interaction term was fitted to test the joint effect of IDU and HCV coinfection in a separate model. A sensitivity analysis was also conducted excluding women with a diagnosis of tuberculosis due to possible hepatic involvement. Statistical analysis was performed using STATA version 13 (Stata Corp LP, College Station USA).

\section{Results}

A third $(n=677)$ of the 2050 HIV-positive women were HCV seropositive. Table 1 shows socio-demographic and clinical characteristics by HCV serostatus. Median age was 27.7 years (IQR 24.6-31.3). One-fifth of women had an IDU history, of whom $79 \%(314 / 398)$ had HCV antibodies, compared with $23 \%$ (333/1461) of those without IDU history. HCV-seropositive women were older than $\mathrm{HCV}$-seronegative women (Table 1). HIV diagnosis occurred a median 16.5 months (IQR 8.6-35.9) prior to enrolment, for two-thirds during their most recent pregnancy. Almost all $(96 \%, 1810 / 1879)$ women had received antenatal ART, with $28 \%(575 / 2029)$ on ART at postnatal cohort enrolment, at a median of 5.0 months (IQR 1.1-10.0) postpartum. Among the 37\% (758/2050) of women with a CD4 count $\leq 350$ cells $/ \mathrm{mm}^{3}$ or WHO stage 3 or 4 disease (i.e. indications for treatment according to WHO guidelines at the time), postnatal treatment coverage was $61 \%(459 / 758)$, with no difference by $\mathrm{HCV}$ serostatus $\left(x^{2}=0.08 p=0.77\right)$. Among 512 with data available on type of ART received postnatally, $75 \%$ $(n=385)$ were on a ritonavir-boosted lopinavir-based regimen (of whom 249 received lopinavir in combination with zidovudine and lamivudine) and $17 \%(n=86)$ were on a nevirapine-based regimen. Of 329 HBV infected women, 115 were on ART postnatally and 107 had information available on type of ART; among these 107, 35 (33\%) were on a tenofovir-containing regimen. Of $6 \%$ $(109 / 1783)$ who conceived their most recent pregnancy while on ART, almost all $(n=103)$ remained on ART postnatally. Only $1 \%(7 / 558)$ with data available had received HCV treatment by enrolment.

\section{HCV genotype and viral load}

Among the sub-group of $56 \mathrm{HCV}$-seropositive women tested for HCV RNA and GT (median 32.0 years), IDU history was reported in 39\% (21/54); none were positive for HBsAg. Ten (18\%) were non-viremic for HCV. Among 46 women with detectable HCV RNA (i.e. $>200$ copies $/ \mathrm{ml}$ ) median viral load was $\log _{10} 5.58$ copies $/ \mathrm{ml}$ (IQR 5.18-6.08): 9 (20\%) had GT1a, 20 (43\%) GT1b, 1 
Table 1 Socio-demographic and clinical characteristics by HCV serostatus at postnatal cohort enrolment

\begin{tabular}{|c|c|c|c|c|}
\hline & Total $(n=2050)$ & HCV antibody negative $(n=1383)$ & HCV antibody positive $(n=667)$ & $p$ value \\
\hline & $n(\%)$ or median & QR] & & \\
\hline Age $(n=2047)$ (years) & $\begin{array}{l}27.7 \\
{[24.6,31.3]}\end{array}$ & $\begin{array}{l}27.1 \\
{[24.1,30.6]}\end{array}$ & $\begin{array}{l}29.1 \\
{[26.2,32.6]}\end{array}$ & $p<0.01$ \\
\hline Age at leaving full-time education $(n=1429)^{a}$ & & & & \\
\hline$\leq 16$ years & $331(23)$ & $159(17)$ & $172(34)$ & $p<0.01$ \\
\hline $17-18$ years & $378(26)$ & $249(27)$ & $129(25)$ & \\
\hline$\geq 19$ years & $720(50)$ & $515(56)$ & $205(41)$ & \\
\hline History of IDU $(n=1859)$ & & & & \\
\hline No & $1461(79)$ & $1128(93)$ & $333(51)$ & $p<0.01$ \\
\hline Yes & $398(21)$ & $84(7)$ & $314(49)$ & \\
\hline Ever had an IDU sex partner $(n=1765)$ & & & & \\
\hline No & $1416(80)$ & $1025(87)$ & $391(66)$ & $p<0.01$ \\
\hline Yes & $349(20)$ & $149(13)$ & $200(34)$ & \\
\hline History of imprisonment $(n=1930)$ & & & & \\
\hline No & $1862(96)$ & $1274(99)$ & $588(92)$ & $p<0.01$ \\
\hline Yes & $68(4)$ & $16(1)$ & $52(8)$ & \\
\hline Timing of HIV diagnosis $(n=1873)^{a}$ & & & & \\
\hline Before most recent pregnancy & $701(37)$ & $398(32)$ & $303(48)$ & $p<0.01$ \\
\hline During most recent pregnancy & $1172(63)$ & $842(68)$ & $330(52)$ & \\
\hline CD4 count $(n=1918),\left(\right.$ cells $/ \mathrm{mm}^{3}$, median [IQR]) & $452[324,604]$ & $460[335,609]$ & $426[299,591]$ & $p<0.01$ \\
\hline CD4 count $(n=1918)$ & & & & \\
\hline$\leq 350$ cells $/ \mathrm{mm}^{3}$ & $566(30)$ & $356(28)$ & $210(33)$ & $p=0.03$ \\
\hline 351-500 cells $/ \mathrm{mm}^{3}$ & $582(30)$ & $395(31)$ & $187(30)$ & \\
\hline$>500 \mathrm{cell} / \mathrm{s} / \mathrm{mm}^{3}$ & $770(40)$ & $538(42)$ & $232(37)$ & \\
\hline WHO stage $(n=2041)$ & & & & \\
\hline Stage 1 & $1424(70)$ & $1065(77)$ & $359(54)$ & $p<0.01$ \\
\hline Stage 2 & $269(13)$ & $145(11)$ & $124(19)$ & \\
\hline Stage 3 & $267(13)$ & $124(9)$ & $143(21)$ & \\
\hline Stage 4 & $81(4)$ & $41(3)$ & $40(6)$ & \\
\hline On ART $(n=2029)$ & & & & \\
\hline No & $1454(72)$ & $1012(74)$ & $442(67)$ & $p<0.01$ \\
\hline Yes & $575(28)$ & $357(26)$ & $218(33)$ & \\
\hline Hepatitis B co-infection $(n=1955)$ & & & & \\
\hline No & $1626(83)$ & $1170(86)$ & $456(76)$ & $p<0.01$ \\
\hline Yes & $329(17)$ & $184(14)$ & $145(24)$ & \\
\hline Smoking history $(n=2021)$ & & & & \\
\hline Never smoked & $578(29)$ & $460(34)$ & $118(18)$ & $p<0.01$ \\
\hline Past smoker & $484(24)$ & $364(27)$ & $120(18)$ & \\
\hline Current smoker, $<15$ cigarettes /day & $417(21)$ & $304(22)$ & $113(17)$ & \\
\hline Current heavy smoker, $\geq 15$ cigarettes /day & $440(22)$ & $176(13)$ & $264(40)$ & \\
\hline Current smoker, cigarettes/day not reported & $102(5)$ & $57(4)$ & $45(7)$ & \\
\hline
\end{tabular}

${ }^{a}$ Available for women with matched pregnancy data from the ECS only 
uncategorised GT1 and 16 (35\%) GT3a. HCV GT1 predominated among those with and without an IDU history (found in 11/18 and 18/27 respectively).

\section{Markers of liver injury or fibrosis}

Figure 1 indicates the number of women with APRI and/or FIB-4 available; this group were similar to those without APRI and/or FIB-4 in terms of $\mathrm{HCV}$ coinfection (30\% (231/762) vs 33\% (342/1031) respectively, $p=0.20)$, IDU history (20\% in each group (150/753 and 203/997) $p=0.82$ ) and age (Wilcoxon-Mann-Whitney rank sum test $p=0.66$ ); however, women with an APRI score were more likely to have WHO stage 3-4 HIV disease than those without $(20 \%(149 / 758)$ vs $16 \%(164 /$
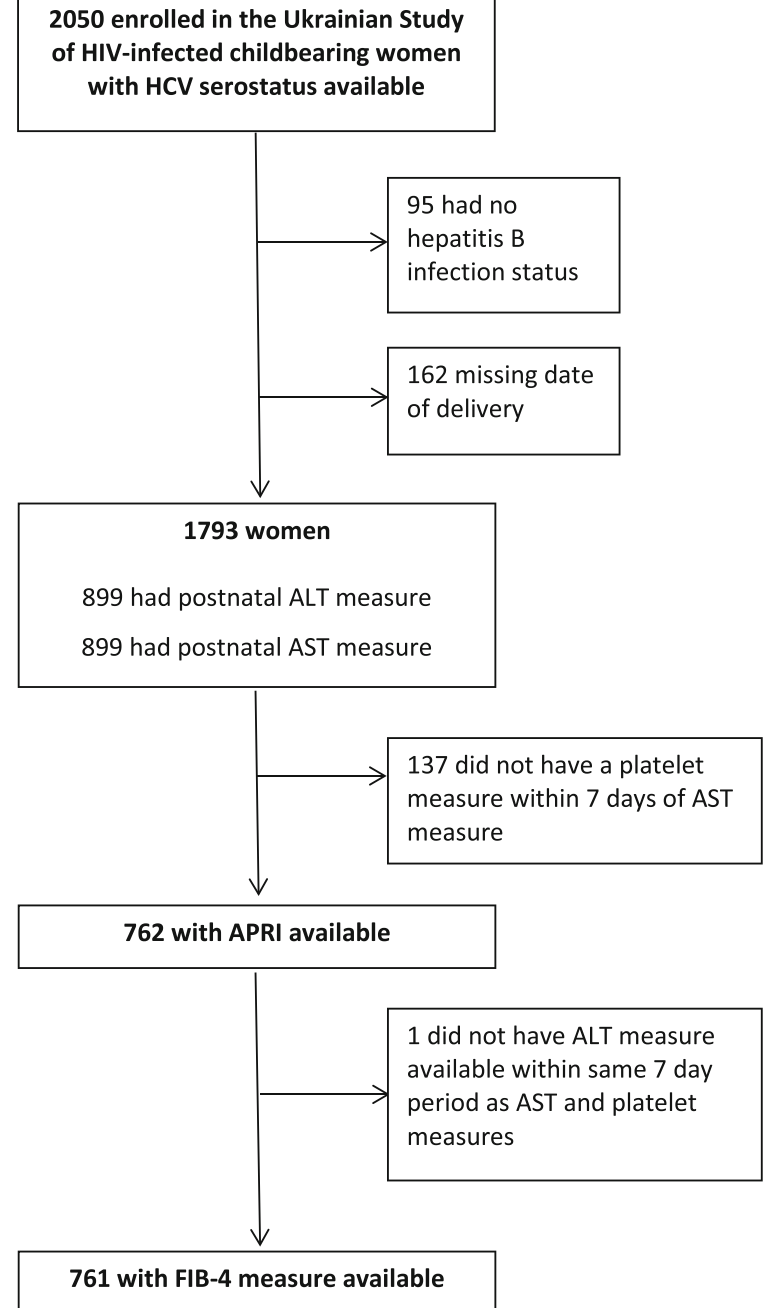

Fig. 1 Availability of surrogate biomarkers of liver fibrosis. Footnote: The APRI /FIB-4 score was available a median of 5.9 months [IQR 3.8-7.3] after delivery, with 56\% ( $n=424)$ having the required blood tests score reported at postnatal cohort enrolment and $44 \%(n=338)$ at a follow-up visit
$1030), p=0.04)$ and HBV co-infection (19\% (146/762) vs $16 \%(161 / 1031)$ respectively, $p=0.049)$.

Table 2 shows markers of liver injury and fibrosis by co-infection status. Among 899 women with liver enzyme data, median AST and ALT levels were $30 \mathrm{U} / \mathrm{L}$ (IQR 19-47) and $24 \mathrm{U} / \mathrm{L}$ (IQR 18-39) respectively. Among the HIV/HCV co-infected women, just over half had ALT levels above $41 \mathrm{U} / \mathrm{L}$ and $84 \%$ had a level above $19 \mathrm{U} / \mathrm{L} ; 61 \%$ had AST above ULN of $38 \mathrm{U} / \mathrm{L}$ (Table 2). Overall 4.5\% (34/762) women had an APRI score $>1.5$, indicating significant fibrosis, and 1\% (9/761) of women had a FIB-4 score $>3.25$, indicating advanced fibrosis. HCV co-infected women had higher FIB-4 scores overall than those without HCV infection (Table 2, WilcoxonMann-Whitney rank-sum test $p<0.01)$ and were less likely to have a FIB-4 score $<1.45$ (Table 2).

\section{Factors associated with significant fibrosis (APRI $>1.5$ )}

In univariable analyses, APRI score $>1.5$ was associated with $\mathrm{HCV}$ seropositivity, IDU history, more advanced HIV disease, smoking and increasing age (Table 3). In multivariable analyses adjusting for these factors plus HBV co-infection and postnatal ART, associations between significant fibrosis and $\mathrm{HCV}$ co-infection, IDU history and more advanced HIV disease were all attenuated (reflecting their inter-correlation) but remained statistically significant (Table 3). Smoking and age were no longer associated with risk of significant fibrosis, however women on ART were less likely to have an APRI score $>1.5$ than untreated women.

Although IDU history and WHO stage remained independently associated with APRI score $>1.5$ after adjusting for $\mathrm{HCV}$ co-infection, there was a significant interaction between IDU history and $\mathrm{HCV}$ co-infection status $(p=0.031)$. Fitting the final model above, but restricted to HIV/HCV co-infected women $(n=219)$, showed that IDU was not associated with significant fibrosis (AOR 2.30, 95\% CI 0.76-6.95) in this sub-group.

Eighteen women included in the main multivariable model had a tuberculosis diagnosis. In a sensitivity analysis excluding these women, the association between WHO stage 3-4 disease and APRI $>1.5$ remained largely unchanged (AOR $3.7095 \% \mathrm{CI} 1.56-8.78, p=0.003$ ) as did the associations between $\mathrm{HCV}$ co-infection and APRI score $>1.5$ (AOR 2.96, 95\% CI 1.17-7.47, $p=0.022$ ) and IDU and APRI score $>1.5$ (AOR 3.39, 95\% CI 1.32$8.72, p=0.011$ ).

\section{Discussion}

In this cohort of young childbearing HIV-positive women, over half of whom had been diagnosed with HIV in the preceding 18 months, a third were coinfected with $\mathrm{HCV}$. Half of the HIV/HCV co-infected group had an ALT measure above $41 \mathrm{U} / \mathrm{L}$ compared 
Table 2 Markers of liver injury or fibrosis by viral hepatitis co-infection status

\begin{tabular}{|c|c|c|c|c|c|}
\hline & $\begin{array}{l}\text { HIV } \\
\text { Mono-infection }\end{array}$ & $\begin{array}{l}\text { HIV/HCV } \\
\text { Co-infection }\end{array}$ & $\begin{array}{l}\text { HIV/HBV } \\
\text { Co-infection }\end{array}$ & $\begin{array}{l}\text { HIV/HCV/HBV } \\
\text { Co-infection }\end{array}$ & Total \\
\hline & \multicolumn{5}{|c|}{$n(\%)$ or median $[\mathrm{IQR}]$} \\
\hline \multicolumn{6}{|l|}{ ALT } \\
\hline Number with measurement available & 514 & 231 & 91 & 63 & 899 \\
\hline Measure above $19 \mathrm{U} / \mathrm{L}$ & $269(52.3)$ & $195(84.4)$ & $60(65.9)$ & $52(82.5)$ & $576(64.1)$ \\
\hline Measure above $41 \mathrm{U} / \mathrm{L}$ & $64(12.5)$ & $122(52.8)$ & $18(19.8)$ & $11(17.5)$ & $215(23.9)$ \\
\hline \multicolumn{6}{|l|}{ DAIDS grading (ULN taken as $41 \mathrm{U} / \mathrm{L})$} \\
\hline Grade 1, mild & $33(6.4)$ & $72(31.2)$ & $9(9.9)$ & $10(15.9)$ & $124(13.8)$ \\
\hline Grade 2, moderate & $3(0.6)$ & $21(9.1)$ & 0 & 0 & $24(2.7)$ \\
\hline Grade 3 or 4 , severe /potentially life threatening & 0 & $7(3.0)$ & 0 & 0 & $7(0.8)$ \\
\hline \multicolumn{6}{|l|}{ AST } \\
\hline Number with measurement available & 514 & 231 & 91 & 63 & 899 \\
\hline Measure above ULN of $38 \mathrm{U} / \mathrm{L}$ & $127(24.7)$ & $141(61.0)$ & $18(19.8)$ & $18(28.6)$ & $304(33.8)$ \\
\hline \multicolumn{6}{|l|}{ DAIDS grading (ULN 38 U/L) } \\
\hline Grade 1, mild & $81(15.8)$ & $86(37.2)$ & $12(13.2)$ & $7(11.1)$ & $186(20.7)$ \\
\hline Grade 2, moderate & $2(0.4)$ & $25(10.8)$ & 0 & $4(6.4)$ & $31(3.5)$ \\
\hline Grade 3 or 4 , severe /potentially life threatening & $1(0.2)$ & $4(1.7)$ & 0 & 0 & $5(0.6)$ \\
\hline \multicolumn{6}{|l|}{ APRI score } \\
\hline Number with measure available & 445 & 171 & 86 & 60 & 762 \\
\hline Median APRI [IQR] & $0.27[0.17,0.42]$ & $0.55[0.30,0.92]$ & $0.23[0.17,0.34]$ & $0.30[0.21,0.43]$ & $0.30[0.18,0.52]$ \\
\hline$<0.5$ (no significant fibrosis) & $358(80.5)$ & $81(47.4)$ & $74(86.1)$ & $48(80.0)$ & $561(73.6)$ \\
\hline $0.5-\leq 1.5$ (intermediate) & $76(17.1)$ & $69(40.4)$ & $12(14.0)$ & $10(16.7)$ & $167(21.9)$ \\
\hline > 1.5 (significant fibrosis) & $11(2.5)$ & $21(12.3)$ & 0 & $2(3.3)$ & $34(4.5)$ \\
\hline \multicolumn{6}{|l|}{ FIB-4 } \\
\hline Number with measure available & 444 & 171 & 86 & 60 & 761 \\
\hline Median FIB-4 [IQR] & $0.61[0.39,0.93]$ & $0.88[0.59,1.47]$ & $0.53[0.36,0.74]$ & $0.68[0.50,0.90]$ & $0.67[0.42,1.01]$ \\
\hline$<1.45$ (no advanced fibrosis) & $403(90.8)$ & $128(74.9)$ & $85(98.8)$ & $53(88.3)$ & $669(87.9)$ \\
\hline 1.45-3.25 (intermediate) & $37(8.3)$ & $41(24.0)$ & $1(1.2)$ & $4(6.7)$ & $83(10.9)$ \\
\hline > 3.25 (advanced fibrosis) & $4(0.9)$ & $2(1.2)$ & 0 & $3(5.0)$ & $9(1.2)$ \\
\hline
\end{tabular}

with one in six of those with HIV mono-infection; the proportions with significant fibrosis (APRI score $>1.5$ ) were $12 \%$ and $2.5 \%$ respectively. Overall, $84 \%$ of HIV/ HCV co-infected women had an ALT measure above 19 U/L (a level found to have $76 \%$ sensitivity in identifying $\mathrm{HCV}$ viraemia among $209 \mathrm{HCV}$ antibody positive blood donors in Italy [21]). A more detailed characterisation of HCV RNA in a sub-group of women indicated a likely spontaneous clearance rate of around 18\% (compared with $23 \%$ in a pan-European study of HIV-positive patients [24]) and a predominance of GT1, although with one-third having GT3 infection.

Factors associated with increased risk of significant fibrosis in adjusted analyses were $\mathrm{HCV}$ co-infection, IDU history, more advanced HIV disease, and no postnatal ART. Overall, $17 \%$ of women were HBV co-infected, increasing to $24 \%$ among those $\mathrm{HCV}$-seropositive.
Hepatitis B has been associated with more rapid liver fibrosis progression among HIV mono-infected and HIV/ HCV co-infected individuals $[25,26]$ but its role in liver fibrosis progression may be complicated by potential interactions of hepatitis B and/or delta virus with HCV to suppress HCV viremia, or vice versa [27, 28]. HBsAgpositive women were less likely to have significant fibrosis than HBsAg-negative women in adjusted analyses, although this did not reach statistical significance $(p=$ $0.085)$. Increasing age was not associated with significant fibrosis in this young cohort, with median age 28 years.

Prevalence of $\mathrm{HCV}$ co-infection among HIV-positive women with an IDU history here was 79\%, in line with previous estimates for Ukraine [29] and more generally for IDUs in transitional countries [30]. Women with a history of IDU had increased risk of significant fibrosis even after adjusting for $\mathrm{HCV}$ and $\mathrm{HBV}$ co-infection, 
Table 3 Factors associated with APRI score $>1.5$

\begin{tabular}{|c|c|c|c|c|c|}
\hline & Proportion with APRI >1.5 (significant fibrosis) & $\begin{array}{l}\text { Odds ratio } \\
(n=726)\end{array}$ & $p$ value & Adjusted odds ratio $(n=726)$ & $p$ value \\
\hline \multicolumn{6}{|c|}{ Hepatitis $C$ antibody status } \\
\hline Negative & $2.1 \%(11 / 531)$ & 1.00 & & 1.00 & \\
\hline Positive & $10.0 \%(23 / 231)$ & $5.16(2.50-10.65)$ & $<0.001$ & $2.53(1.03-6.23)$ & 0.044 \\
\hline \multicolumn{6}{|c|}{ Hepatitis B surface antigen } \\
\hline Positive & $1.4 \%(2 / 146)$ & 1.00 & & 1.00 & \\
\hline Negative & $5.2 \%(32 / 616)$ & $3.28(0.89-12.02)$ & 0.074 & $3.28(0.85-12.71)$ & 0.085 \\
\hline \multicolumn{6}{|c|}{ History of injecting drug use } \\
\hline No & $1.8 \%(11 / 603)$ & 1.00 & & 1.00 & \\
\hline Yes & $15.3 \%(23 / 150)$ & $9.15(4.40-19.01)$ & $<0.001$ & $3.51(1.39-8.89)$ & 0.008 \\
\hline \multicolumn{6}{|l|}{ WHO stage ${ }^{a}$} \\
\hline $1-2$ & $2.6 \%(16 / 605)$ & 1.00 & & 1.00 & \\
\hline $3-4$ & $12.4 \%(18 / 145)$ & $5.02(2.52-10.02)$ & $<0.001$ & $3.47(1.51-7.99)$ & 0.003 \\
\hline \multicolumn{6}{|l|}{ CD4 count $^{a}$} \\
\hline$>350$ cells $/ \mathrm{mm}^{3}$ & $3.9 \%(22 / 563)$ & 1.00 & & & \\
\hline 201-350 cells $/ \mathrm{mm}^{3}$ & $5.3 \%(7 / 132)$ & $1.46(0.62-3.42)$ & 0.381 & & \\
\hline$\leq 200$ cells $/ \mathrm{mm}^{3}$ & $8.2 \%(4 / 49)$ & $2.32(0.80-6.67)$ & 0.119 & & \\
\hline \multicolumn{6}{|c|}{ Smoker at postnatal cohort enrolment } \\
\hline No & $2.7 \%(11 / 409)$ & 1.00 & & 1.00 & \\
\hline Yes, current smoker & $6.8 \%(23 / 340)$ & $2.59(1.26-5.33)$ & 0.010 & $1.06(0.46-2.42)$ & 0.896 \\
\hline \multicolumn{6}{|l|}{ Age } \\
\hline Per increasing year & & $1.10(1.03-1.18)$ & 0.007 & $1.08(0.99-1.18)$ & 0.070 \\
\hline \multicolumn{6}{|l|}{ Postnatal ART ${ }^{\mathrm{b}}$} \\
\hline Yes & $4.0 \%(10 / 253)$ & 1.00 & & 1.00 & \\
\hline No & $4.8 \%(24 / 500)$ & $1.15(0.55-2.41)$ & 0.715 & $3.08(1.23-7.74)$ & 0.017 \\
\hline
\end{tabular}

${ }^{a}$ Closest to timing of liver function test measures ${ }^{b}$ At postnatal cohort enrolment

possibly reflecting hepatotoxic effects of injected substances. Homemade poppy straw is the drug most commonly injected in Ukraine and in this cohort [18], usually taken with a range of other drugs [31] which may cause liver transaminase elevation. Injecting drug use has itself also been associated with thrombocytopenia [32], which would result in a higher APRI score; however, APRI has been validated in $\mathrm{HCV}$ infected individuals among whom IDU is common.

ART coverage was suboptimal, reflecting the national situation - only $26 \%$ of adults living with HIV in Ukraine were estimated to be receiving ART in 2013 [33]; here, over a third of women with treatment indications were not on cART postnatally. Among HIVpositive people living in Eastern Europe have a higher incidence of AIDS-related death and lower incidence of liver-related death than those in the West, reflecting poorer cART coverage [34]; the proportion of deaths attributable to liver disease in Eastern Europe can be expected to rise as coverage of cART increases.
We found that women with advanced /severe HIV disease had a more than three-fold increased risk of significant fibrosis, indicating accelerated liver fibrosis associated with high HIV RNA load and/or the presence of AIDS-defining diseases with hepatic involvement [35]. Almost three-quarters had stopped antenatal ART by postnatal cohort enrolment, reflecting the national prevention of mother-to-child transmission (PMTCT) policy at the time, and untreated women were at independently increased risk of significant fibrosis. ART interruptions and/or rebounds in HIV RNA have been associated with more rapid liver fibrosis progression in HIV/HCV co-infection patients [36], and short course ART for PMTCT may be particularly detrimental for this group's longer term prognosis. Option B+ (lifelong ART initiated in all pregnant women with HIV) became national policy in Ukraine in 2015 and may help to improve postnatal cART coverage, with concomitant reductions in liver fibrosis progression [37-39].

Among non-IDUs, the $23 \% \mathrm{HCV}$ co-infection prevalence points to potential under-ascertainment of IDU, 
but also other modes of $\mathrm{HCV}$ acquisition including iatrogenic acquisition or household/ sexual acquisition from IDU partners. Heterosexual $\mathrm{HCV}$ acquisition risk may be substantially increased with HIV co-infection [40] and our study population are at high risk of other sexually transmitted infections [41] which may act to synergistically to increase risk of sexual HCV acquisition. Improved understanding of modes of $\mathrm{HCV}$ transmission in this population is crucial for informing prevention strategies, including reducing $\mathrm{HCV}$ re-infections following $\mathrm{HCV}$ treatment.

Other published studies of hepatic fibrosis in HIV/ $\mathrm{HCV}$ co-infection predominantly include older individuals, the majority males and IDUs, limiting comparisons with our study. Half of $73 \mathrm{HIV} / \mathrm{HCV}$ co-infected women in the Women's Interagency HIV Study had significant fibrosis (defined as liver stiffness $\geq 7.1 \mathrm{kPa}$ by transient elastography) [42] while $24 \%$ of $800 \mathrm{HIV} / \mathrm{HCV}$ coinfected patients (30\% female) enrolled in the Canadian Coinfection Cohort Study had an APRI score $\geq 1.5$ [43], similar to $20 \%$ in a cohort of $116 \mathrm{HIV} / \mathrm{HCV}$ co-infected patients (36\% female) in France, with median age 44 years [44]. Although the HIV/HCV co-infected women here were 13-15 years younger than individuals in these studies, $12 \%$ already had significant fibrosis. Future rates of progression will depend on modifiable risk factors, for example increasing cART and availability of $\mathrm{HCV}$ treatment. In the Canadian Coinfection Cohort Study, the incidence rate for progression to an APRI score $\geq 1.5$ was $14.0 / 100$ person-years among $\mathrm{HIV} / \mathrm{HCV}$ co-infected women vs. 8.9/100 person-years among men [9], thus, the HIV/HCV co-infected women in our cohort may represent a high risk group for developing significant liver fibrosis based on their gender as well as current fibrosis rates.

$\mathrm{HCV}$ treatment was not publicly funded in Ukraine at the time of our study. In 2014 a national HCV treatment programme was launched based on interferon, and in 2015 this was extended to include sofosbuvir, with a Global Fund-supported pilot scheme also aiming to provide sofosbuvir treatment to 1500 patients from priority groups including those with HIV co-infection, from mid2015 [45]. The expansion of HCV treatment access alongside high quality HIV treatment and care is crucial to prevent avoidable morbidity in HIV/HCV co-infected people in Ukraine, while in childbearing women the successful treatment of $\mathrm{HCV}$ could also prevent perinatal transmissions in future pregnancies.

This study had several limitations. APRI may perform less well in HIV/HCV co-infection than in HCV monoinfection, but the $>1.5$ cut-off used here is highly specific for significant fibrosis $(0.95,95 \%$ CI 0.92-0.97) with lower sensitivity $(0.2795 \%$ CI $0.23-0.31)$ [46]; the prevalence of significant fibrosis we report should therefore be considered a minimum estimate. Information on duration of diagnosed HCV was not available (age was used as a proxy) and we also lacked information on other factors relevant to liver injury, for example alcohol consumption, other medications and indicators of metabolic syndrome; body mass index was not interpretable in this cohort of recently delivered women. Elevated transaminases were based on one measure only as we lacked repeated measures, and we did not have information on delta virus which may contribute to fibrosis progression among those with hepatitis B. As HCV RNA quantification is not routine in Ukraine, our definition of HCV co-infection was based on HCV serostatus (in common with other studies of HIV/HCV co-infection [7]) and so will have included some women who had spontaneously cleared the virus; the proportion of $\mathrm{HCV}$ viremic women with APRI score $>1.5$ may therefore be higher than our estimates for the HIV/HCV co-infected group suggest. Resources to support HCV RNA and GT testing were available for $56 \mathrm{HIV} / \mathrm{HCV}$ co-infected women only as part of this study. Liver biopsy and/or transient elastography were not available to validate the non-invasive markers used in this study, reflecting lack of use / availability in participating HIV centres. Women with WHO stage 3-4 disease were more likely to have an APRI score available than those with less severe HIV disease. Women in this study were engaged with HIV care and may have a different liver fibrosis risk profile to the wider HIV-positive population.

\section{Conclusions}

There is a high burden of HCV co-infection among childbearing women living with HIV in Ukraine, particularly among those with an IDU history. Most HIV/HCV co-infected women had elevated liver enzymes indicating liver injury, and $12 \%$ had significant fibrosis according to their APRI scores. HCV treatment rates were extremely low and a high proportion of this population of postnatal women were not on ART, a situation which is likely to have changed now that Ukraine has adopted an Option $\mathrm{B}+$ policy. Our results highlight the importance of addressing modifiable risk factors and roll-out of $\mathrm{HCV}$ treatment for improving longer term prognosis.

\section{Abbreviations \\ (c)ART: (combination) antiretroviral therapy; ALT: Alanine aminotransferase; APRI: AST to platelet ratio; AST: Aspartate transaminase; DAIDS: Division of AIDS; ECS: European Collaborative Study; GT: Genotype; HBsAg: Hepatitis B surface antigen; HCV: Hepatitis C virus; IDU: Injecting drug use; \\ IQR: Interquartile range; PMTCT: Prevention of mother-to-child transmission; ULN: Upper limit of normal; WHO: World Health Organisation}

\section{Acknowledgements}

We thank the women who took part in this study. The Ukraine ECS group consists of the following members who contributed to this work: T. Pilipenko (Perinatal Prevention of AIDS Initiative, Odessa); S. Posokhova (Regional Hospital, Odessa); T. Kaleeva, Y. Barishnikova, S. Servetsky, R. Tereshenko (Odessa Regional Centre for HIV/AIDS); Svetlana Solokha, M. P. Grazhdanov, E. Kulakovskaya (Donetsk Regional Centre for HIV/AIDS); I. Raus, O. V.

Yurchenko, I. Adejnova (Kiev City Centre for HIV/AIDS); Z. Ruban, O.Govorun, 
I. Kochergina, L. Ostrovskaya (Mykolaiv Regional Centre for HIV/AIDS); N Primak; L. Kvasha, G. Kruglenko (Kriviy Rig City Center for HIV/AIDS). We acknowledge the support of I Kuzin and colleagues at the Ukrainian Center for Socially Dangerous Disease Control of the Ministry of Health of Ukraine. Study data for the sub-study on HCV genotype and viral load were collected and managed using REDCap electronic data capture tools hosted at UCL [47]. REDCap (Research Electronic Data Capture) is a secure, web-based application designed to support data capture for research studies and receives grant support UL1 TR000445 from NCATS/NIH.

\section{Funding}

The Ukraine European Collaborative Study received funding from the European Union's Seventh Framework Programme for research, technological development and demonstration under EuroCoord grant agreement $n^{\circ} 260694$. Claire Thorne held a Wellcome Trust Research Career Development Fellowship which supported the Ukrainian Study of HIV-infected Childbearing Women (grant number 081082). Funding for additional HCV RNA and GT tests for this work was provided by an MRC Centenary Award held by Heather Bailey. Some of this work was undertaken at GOSH/UCL Institute of Child Health which received a proportion of funding from the UK Department of Health's NIHR Biomedical Research Centres funding scheme. The UCL Institute of Child Health Population, Policy and Practice Programme also benefitted from funding support from the MRC in its former capacity as the MRC Centre of Epidemiology for Child Health (grant number G0400546). The funders of this work had no role in the study design; in collection, analysis, and interpretation of data; in the writing of the report; or the decision to submit the manuscript for publication.

\section{Availability of data and material}

The datasets generated during and/or analysed during the current study are not publicly available due to the highly sensitive nature of the data (an observational study of HIV-positive childbearing women including drug use history) and potentially disclosive nature of some data items in combination, including year of HIV diagnosis and delivery. Anonymised data extracts are available from the corresponding author on reasonable request.

\section{Authors' contributions}

$H B, A V, R M$ and $C T$ designed the study. $H B$ and $M C B$ analysed the data. $H B$ drafted the manuscript. $H B, N N, V M, A V, R M, M C B$ and $C T$ interpreted the data, revised the manuscript for important intellectual content and read and approved the final manuscript.

\section{Authors' information}

No additional information applicable.

\section{Competing interests}

The authors declare that they have no competing interests.

\section{Consent for publication}

N/A

\section{Ethics approval and consent to participate}

The ECS has ethics approval from the Great Ormond Street Hospital for Children NHS Trust/Institute of Child Health Research Ethics Committee (reference 96EB02). This included approval of the procedure of obtaining verbal and not written consent from participating women, given the anonymous nature of the study. Furthermore, within the The Ukrainian Study of HIV-infected Childbearing Women protocol, women were required to complete an anonymised questionnaire at enrolment; the return of this questionnaire by the woman was taken as documentation and evidence of her consent to participate. Ethics approval for additional HCV RNA and GT testing conducted with consent as part of this study was obtained from the UCL Research Ethics Committee (3061/002) and from the Ethics Committee of the Shupyk National Medical Academy of Postgraduate Education in Kiev.

\section{Disclosures}

$\mathrm{CT}$ has received funding from the UK Medical Research Council, Public Health England, UNICEF, the PENTA Foundation and AbbVie. HB has received funding from the UK Medical Research Council, the International AIDS Society and Public Health England.

\section{Author details}

${ }^{1}$ Population, Policy and Practice Programme, UCL Great Ormond Street Institute of Child Health, University College London, 30 Guilford Street, London WC1N 1EH, UK. ${ }^{2}$ The Public Health Center of the Ministry of Health of Ukraine, Kyiv, Ukraine. ${ }^{3}$ Institute of Epidemiology and Infectious Diseases of NAMS, Kiev, Ukraine. ${ }^{4}$ Shupyk National Medical Academy of Postgraduate Education, Kiev, Ukraine. ${ }^{5}$ Perinatal Prevention of AIDS Initiative, Odessa, Ukraine.

Received: 9 September 2016 Accepted: 3 December 2016

Published online: 12 December 2016

\section{References}

1. Mohd Hanafiah K, Groeger J, Flaxman AD, Wiersma ST. Global epidemiology of hepatitis C virus infection: new estimates of age-specific antibody to HCV seroprevalence. Hepatology. 2013;57(4):1333-42.

2. Hope VD, Eramova I, Capurro D, Donoghoe MC. Prevalence and estimation of hepatitis B and C infections in the WHO European Region: a review of data focusing on the countries outside the European Union and the European Free Trade Association. Epidemiol Infect. 2014;142(2):270-86.

3. Platt L, Easterbrook P, Gower E, McDonald B, Sabin K, McGowan C, Yanny I, Razavi $\mathrm{H}$, Vickerman P. Prevalence and burden of HCV co-infection in people living with HIV: a global systematic review and meta-analysis. Lancet Infect Dis. 2016

4. Messina JP, Humphreys I, Flaxman A, Brown A, Cooke GS, Pybus OG, Barnes E. Global distribution and prevalence of hepatitis $C$ virus genotypes. Hepatology. 2015;61(1):77-87.

5. Weber R, Sabin CA, Friis-Moller N, Reiss P, El-Sadr WM, Kirk O, Dabis F, Law MG, Pradier C, De Wit S, et al. Liver-related deaths in persons infected with the human immunodeficiency virus: the D:A:D study. Arch Intern Med. 2006; 166(15):1632-41.

6. de Ledinghen V, Barreiro P, Foucher J, Labarga P, Castera L, Vispo ME, Bernard PH, Martin-Carbonero L, Neau D, Garcia-Gasco P, et al. Liver fibrosis on account of chronic hepatitis $C$ is more severe in HIV-positive than HIVnegative patients despite antiretroviral therapy. J Viral Hepat. 2008;15(6): 427-33

7. Klein MB, Rollet-Kurhajec KC, Moodie EE, Yaphe S, Tyndall M, Walmsley S, Gill J, Martel-Laferriere V, Cooper C, Canadian Co-infection Cohort I. Mortality in HIV-hepatitis C co-infected patients in Canada compared to the general Canadian population (2003-2013). AIDS. 2014;28(13):1957-65.

8. Poynard T, Bedossa P, Opolon P. Natural history of liver fibrosis progression in patients with chronic hepatitis C. The OBSVIRC, METAVIR, CLINIVIR, and DOSVIRC groups. Lancet. 1997;349(9055):825-32.

9. Rollet-Kurhajec KC, Moodie EE, Walmsley S, Cooper C, Pick N, Klein MB, Canadian Co-infection Cohort S. Hepatic Fibrosis Progression in HIVHepatitis C Virus Co-Infection-The Effect of Sex on Risk of Significant Fibrosis Measured by Aspartate-to-Platelet Ratio Index. PLoS One. 2015;10(6), e0129868.

10. Arends JE, Lieveld FI, Boeijen LL, de Kanter CT, van Erpecum KJ, Salmon D, Hoepelman Al, Asselah T, Ustianowski A. Natural history and treatment of HCV/HIV coinfection: Is it time to change paradigms? J Hepatol. 2015;63(5): 1254-62.

11. Benova L, Mohamoud YA, Calvert C, Abu-Raddad L. Vertical transmission of hepatitis C virus: systematic review and meta-analysis. Clin Infect Dis. 2014; 59(6):765-73

12. European Association for the Study of the Liver (EASL): EASL Clinical Practice Guidelines. In. 2016. Available at http://www.easl.eu/research/ourcontributions/clinical-practice-guidelines/detail/recommendations-ontreatment-of-hepatitis-c-2015/report/4. Accessed June 2016.

13. Childs K, Taylor C, Dieterich D, Agarwal K. Directly acting antivirals for hepatitis $C$ virus arrive in HIV/hepatitis C virus co-infected patients: from 'mind the gap' to 'where's the gap?'. AIDS. 2016;30(7):975-89.

14. American Association for the Study of Liver Diseases (AASLD), Infectious Diseases Society of America: Recommendations for Testing, Managing, and Treating Hepatitis C. In. 2016. Available at http://www.hcvguidelines.org, accessed June 2016.

15. Hill A, Khoo S, Fortunak J, Simmons B, Ford N. Minimum costs for producing hepatitis $C$ direct-acting antivirals for use in large-scale treatment access programs in developing countries. Clin Infect Dis. 2014;58(7):928-36.

16. Wai CT, Greenson JK, Fontana RJ, Kalbfleisch JD, Marrero JA, Conjeevaram HS, Lok AS. A simple noninvasive index can predict both significant fibrosis 
and cirrhosis in patients with chronic hepatitis C. Hepatology. 2003;38(2): 518-26.

17. Sterling RK, Lissen E, Clumeck N, Sola R, Correa MC, Montaner J, Sulkowski S, Torriani FJ, Dieterich DT, Thomas DL, et al. Development of a simple noninvasive index to predict significant fibrosis in patients with HIV/HCV coinfection. Hepatology. 2006;43(6):1317-25.

18. Thorne C, Semenenko I, Malyuta R. Prevention of mother-to-child transmission of human immunodeficiency virus among pregnant women using injecting drugs in Ukraine, 2000-10. Addiction. 2012;107(1):118-28.

19. Bagkeris E, Malyuta R, Volokha A, Cortina-Borja M, Bailey $H$, Townsend CL, Thorne C, Ukraine European Collaborative Study in E. Pregnancy outcomes in HIV-positive women in Ukraine, 2000-12 (European Collaborative Study in EuroCoord): an observational cohort study. The lancet HIV. 2015;2(9):e385-392.

20. Abbassi-Ghanavati M, Greer LG, Cunningham FG. Pregnancy and laboratory studies: a reference table for clinicians. Obstet Gynecol. 2009;114(6):1326-31.

21. Prati D, Taioli E, Zanella A, Della Torre E, Butelli S, Del Vecchio E, Vianello L, Zanuso F, Mozzi F, Milani S, et al. Updated definitions of healthy ranges for serum alanine aminotransferase levels. Ann Intern Med. 2002;137(1):1-10.

22. Division of AIDS: Division of AIDS table for grading the severity of adult and pediatric adverse events. Version 1.0, December 2004; clarification August 2009. In.; 2009. Bethesda: National Institutes of Health.

23. Bandstra ES, Morrow CE, Mansoor E, Accornero VH. Prenatal drug exposure: infant and toddler outcomes. J Addict Dis. 2010;29(2):245-58.

24. Soriano V, Mocroft A, Rockstroh J, Ledergerber B, Knysz B, Chaplinskas S, Peters L, Karlsson A, Katlama C, Toro C, et al. Spontaneous viral clearance, viral load, and genotype distribution of hepatitis C virus (HCV) in HIVinfected patients with anti-HCV antibodies in Europe. J Infect Dis. 2008; 198(9):1337-44.

25. Sanmartin R, Tor J, Sanvisens A, Lopez JJ, Jou A, Muga R, Ojanguren I, Barluenga E, Videla S, Planas R, et al. Progression of liver fibrosis in HIV/ hepatitis $C$ virus-coinfected individuals on antiretroviral therapy with early stages of liver fibrosis at baseline. HIV Med. 2014;15(4):203-12.

26. Kim HN, Nance R, Van Rompaey S, Delaney JC, Crane HM, Cachay ER, Geng E, Boswell SL, Rodriguez B, Eron J et al: Poorly Controlled HIV Infection: An Independent Risk Factor for Liver Fibrosis. J Acquir Immune Defic Syndr. 2016; 72(4):437-43

27. Liaw YF. Role of hepatitis $C$ virus in dual and triple hepatitis virus infection. Hepatology. 1995;22(4 Pt 1):1101-8.

28. Antonucci G, Vairo F, lacomi F, Comandini UV, Solmone M, Piselli P, Boumis E, Lauria FN, Capobianchi MR, Ippolito G, et al. Role of hepatitis B virus, hepatitis $D$ virus and other determinants on suppression of hepatitis $C$ viraemia in HIV infected patients with chronic HCV infection: a longitudinal evaluation. Scand J Infect Dis. 2008;40(11-12):928-34.

29. Nelson PK, Mathers BM, Cowie B, Hagan H, Des JD, Horyniak D, Degenhardt L. Global epidemiology of hepatitis B and hepatitis $C$ in people who inject drugs: results of systematic reviews. Lancet. 2011;378(9791):571-83.

30. Hagan H, Pouget ER, Des Jarlais DC, Lelutiu-Weinberger C. Meta-regression of hepatitis $C$ virus infection in relation to time since onset of illicit drug injection: the influence of time and place. Am J Epidemiol. 2008;168(10): 1099-109.

31. Dumchev KV, Soldyshev R, Qian HZ, Zezyulin OO, Chandler SD, Slobodyanyuk P, Moroz L, Schumacher JE. HIV and hepatitis C virus infections among hanka injection drug users in central Ukraine: a crosssectional survey. Harm Reduction J. 2009;6:23.

32. Mientjes $\mathrm{GH}$, van Ameijden EJ, Mulder JW, van den Hoek JA, Coutinho RA, von dem Borne AE. Prevalence of thrombocytopenia in HIV-infected and non-HIV infected drug users and homosexual men. Br J Haematol. 1992; 82(3):615-9.

33. UNAIDS: The Gap Report. In.; 2014. accessible at http://www.unaids.org/sites/ default/files/media_asset/UNAIDS_Gap_report_en.pdf. Accessed May 2016.

34. Grint D, Peters L, Rockstroh JK, Rakmanova A, Trofimova T, Lacombe K, Karpov I, Galli M, Domingo P, Kirk O, et al. Liver-related death among HIV/ hepatitis $C$ virus-co-infected individuals: implications for the era of directly acting antivirals. AIDS. 2015;29(10):1205-15.

35. Price JC, Thio CL. Liver disease in the HIV-infected individual. Clin Gastroenterol Hepatol. 2010;8(12):1002-12.

36. Cooper C, Rollet-Kurhajec KC, Young J, Vasquez C, Tyndall M, Gill J, Pick N, Walmsley S, Klein MB, Canadian Co-infection Cohort Study I. HIV virologica rebounds but not blips predict liver fibrosis progression in antiretroviraltreated HIV/hepatitis C virus-coinfected patients. HIV Med. 2015;16(1):24-31.
37. Qurishi N, Kreuzberg C, Luchters G, Effenberger W, Kupfer B, Sauerbruch T, Rockstroh JK, Spengler U. Effect of antiretroviral therapy on liver-related mortality in patients with HIV and hepatitis C virus coinfection. Lancet. 2003; 362(9397):1708-13.

38. Brau N, Salvatore M, Rios-Bedoya CF, Fernandez-Carbia A, Paronetto F, Rodriguez-Orengo JF, Rodriguez-Torres M. Slower fibrosis progression in HIV/HCV-coinfected patients with successful HIV suppression using antiretroviral therapy. J Hepatol. 2006;44(1):47-55.

39. Macias J, Mira JA, Lopez-Cortes LF, Santos I, Giron-Gonzalez JA, GonzalezSerrano M, Merino D, Hernandez-Quero J, Rivero A, Merchante N, et al. Antiretroviral therapy based on protease inhibitors as a protective factor against liver fibrosis progression in patients with chronic hepatitis C. Antivir Ther. 2006;11(7):839-46.

40. Tohme RA, Holmberg SD. Is sexual contact a major mode of hepatitis C virus transmission? Hepatology. 2010:52(4):1497-505.

41. Aebi-Popp K, Bailey H, Malyuta R, Volokha A, Thorne C, Ukraine European Collaborative Study in EuroCoord. High prevalence of herpes simplex virus (HSV)- type 2 co-infection among HIV-positive women in Ukraine, but no increased HIV mother-to-child transmission risk. BMC Pregnancy Childbirth. 2016;16(1):94

42. Kassaye S, Li Y, Huhn G, Peters MG, French AL, Tien PC, Luxon B, Plankey MW: Direct and Indirect Serum Markers of Liver Fibrosis Compared with Transient Elastography among Women in the Women's Interagency HIV Study. J AIDS Clin Res. 2015;6(4).

43. Brunet L, Moodie EE, Cox J, Gill J, Cooper C, Walmsley S, Rachlis A, Hull M, Klein MB, Canadian Coinfection Cohort Study I. Opioid use and risk of liver fibrosis in HIV/hepatitis C virus-coinfected patients in Canada. HIV Med. 2016;17(1):36-45.

44. Castera L, Winnock M, Pambrun E, Paradis V, Perez P, Loko MA, Asselineau J, Dabis F, Degos F, Salmon D. Comparison of transient elastography (FibroScan), FibroTest, APRI and two algorithms combining these noninvasive tests for liver fibrosis staging in HIV/HCV coinfected patients: ANRS CO13 HEPAVIH and FIBROSTIC collaboration. HIV Med. 2014;15(1):30-9.

45. Civil Society Response to the Epidemic, International HIV/AIDS Alliance in Ukraine, International Treatment Preparedness Coalition in Eastern Europe and Central Asia: Hepatitis C in Eastern Europe and Central Asia: Epidemic and Response. In.; 2015. http://www.aidsalliance.org.ua/ru/news/pdf/28.10. 2015/EECA\%20HCV\%20EN.pdf, accessed May 2016.

46. Lin ZH, Xin YN, Dong QJ, Wang Q, Jiang XJ, Zhan SH, Sun Y, Xuan SY. Performance of the aspartate aminotransferase-to-platelet ratio index for the staging of hepatitis C-related fibrosis: an updated meta-analysis. Hepatology. 2011;53(3):726-36.

47. Harris PA, Taylor R, Thielke R, Payne J, Gonzalez N, Conde JG. Research electronic data capture (REDCap)-A metadata-driven methodology and workflow process for providing translational research informatics support. J Biomed Inform. 2009:42(2):377-81.

\section{Submit your next manuscript to BioMed Central and we will help you at every step:}

- We accept pre-submission inquiries

- Our selector tool helps you to find the most relevant journal

- We provide round the clock customer support

- Convenient online submission

- Thorough peer review

- Inclusion in PubMed and all major indexing services

- Maximum visibility for your research

Submit your manuscript at www.biomedcentral.com/submit 